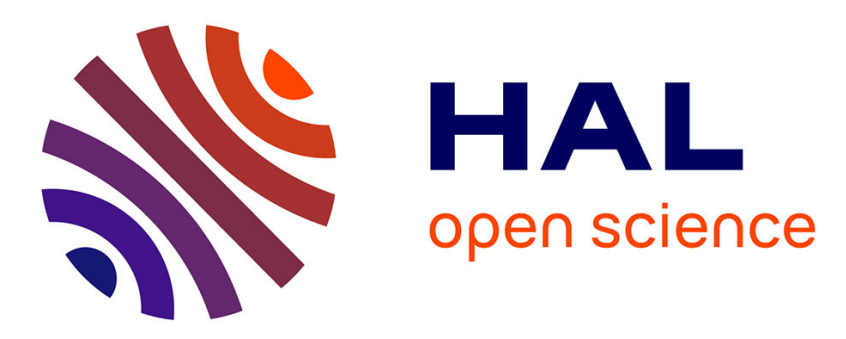

\title{
Water Vapor Binding on Organic Matter-Coated Minerals
}

W. Cheng, K. Hanna, J. -F. Boily

\section{To cite this version:}

W. Cheng, K. Hanna, J. -F. Boily. Water Vapor Binding on Organic Matter-Coated Minerals. Environmental Science and Technology, 2019, 53 (3), pp.1252-1257. 10.1021/acs.est.8b05134. hal02049511

HAL Id: hal-02049511

https://hal-univ-rennes1.archives-ouvertes.fr/hal-02049511

Submitted on 7 Mar 2019

HAL is a multi-disciplinary open access archive for the deposit and dissemination of scientific research documents, whether they are published or not. The documents may come from teaching and research institutions in France or abroad, or from public or private research centers.
L'archive ouverte pluridisciplinaire HAL, est destinée au dépôt et à la diffusion de documents scientifiques de niveau recherche, publiés ou non, émanant des établissements d'enseignement et de recherche français ou étrangers, des laboratoires publics ou privés. 
1

2

3

$4 \quad$ W. Cheng ${ }^{1,2}$, K. Hanna ${ }^{1}$, J.-F. Boily ${ }^{2}$

5 'Univ Rennes, École Nationale Supérieure de Chimie de Rennes, CNRS, ISCR - UMR6226, F-35000

6 Rennes, France

7 2. Department of Chemistry, Umeå University, SE-901 87 Umeå, Sweden

\section{Water vapor binding on organic matter-coated minerals}

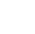

8

9

10

11

12

13

14

15

16

17

18

19

20

21

22

23

24

25

26

27

.

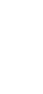

1

3

4

18


ABSTRACT

29 Atmospheric water vapor binding to soils is a key process driving water availability in unsaturated terrestrial 30 environments. Using a representative hydrophilic iron oxyhydroxide, this study highlights key mechanisms 31 through which water vapor $(i)$ adsorbs and (ii) condenses at mineral surfaces coated with Leonardite humic 32 acid (LHA). Microgravimetry and vibrational spectroscopy showed that liquid-like water forms in the three33 dimensional array of mineral-bound LHA when present at total $\mathrm{C} / \mathrm{Fe}$ ratios well exceeding $\sim 240 \mathrm{mg} \mathrm{C}$ per $\mathrm{g}$ 34 Fe. Below these loadings, minerals become even less hydrophilic than in the absence of LHA. This lowering 35 in hydrophilicity is caused by the complexation of LHA water-binding sites to mineral surfaces, and possibly 36 by conformational changes in LHA structure removing available condensation environments for water. An 37 empirical relationship predicting the dependence of water adsorption densities on LHA loadings was 38 developed from these results. Together with the molecular-level description provided in this work, this 39 relationship should guide efforts in predicting water availability, and thereby occurrences of water-driven 40 geochemical processes in terrestrial environments.

41 


\section{INTRODUCTION}

Soil hydrophobicity is a key parameter that describes the extent to which water-based geochemical reactions can proceed, and can be used in environmental monitoring and soil quality assessment. ${ }^{1}$ This concept is a manifestation of the ability to which water vapor flowing through unsaturated soils (e.g. vadose zones) can form thin water films and droplets at and between mineral grains. Knowledge of the propensity of formation of these aqueous environments is consequently essential for predicting water availability, as well as geochemical aqueous reactions taking place within the microscopic solvation environments of water films and droplets.

Understanding the fate of water binding to soils also requires knowledge of the intervening roles of natural organic matter (NOM). Of common occurrence in soils,,${ }^{2-4}$ NOM strongly reacts with mineral surfaces via chemical and/or physical adsorption reactions involving their hydrophilic functional groups (e.g. carboxylates, phenolates, amines), as well as by van der Waals hydrophobic interactions, and cation bridging. ${ }^{5-9}$ These $^{-1}$ organic coatings have a strong propensity to alter the hydrophilicity of mineral surfaces, the extent to which could be determined by the type and concentration of functional groups exposed at the mineral-organic/water vapor interface. Mineral-bound NOM can also alter surface properties of minerals, ${ }^{5}$ and have direct consequences on the mobility and fate of other contaminants, such as organic contaminants and heavy metals, ${ }^{10-14}$ through an interconnected network of water films/droplets localized on organic-coated mineral grains.

Although the concept of soil mineral hydrophobicity is well recognized and its influence on organic compound transport studied, ${ }^{1,11,15}$ its underlying mechanisms remain misunderstood. Still, strong correlations between soil hydrophobicity and soil organic matter ${ }^{16}$ or mineral-sorbed humic substances have been identified. ${ }^{15}$ Building upon our recent work on water vapor binding on minerals ${ }^{17-22}$ and the thermochemical stability of NOM mineral coatings, ${ }^{20}$ this work uses microgravimetry and vibrational spectroscopy to explain and predict water vapor binding to mineral-NOM mixtures. This was achieved by focusing on a model system consisting of Leonardite humic acid (LHA), a representative hydrophilic NOM, and goethite ( $\alpha-\mathrm{FeOOH}), \mathrm{a}$ nanosized mineral with key roles in NOM and contaminant mobility in terrestrial and aquatic environments. ${ }^{23-}$ 26 


\section{MATERIALS AND METHODS}

\section{7}

\subsection{Materials}

Goethite was synthesized by hydrothermal conversion of a freshly precipitated ferric oxyhydroxide at 60 ${ }^{\circ} \mathrm{C}$ for $72 \mathrm{~h} \cdot{ }^{27,28}$ The starting material was made by drop-wise $(1 \mathrm{~mL} / \mathrm{min})$ addition of $500 \mathrm{~mL}$ of a $0.5 \mathrm{M}$ ferric nitrate solution $\left(\mathrm{Fe}\left(\mathrm{NO}_{3}\right)_{3} \cdot 9 \mathrm{H}_{2} \mathrm{O}\right)$ to a continuously stirred $400 \mathrm{~mL}$ of $2.5 \mathrm{M}$ sodium hydroxide solution in a $\mathrm{N}_{2}(\mathrm{~g})$ atmosphere. The resulting goethite was dialyzed (Spectra/Por membrane 2) against ultrapure water. The water was changed every day until its conductivity was lower than $1 \mu \mathrm{S} / \mathrm{cm}$. The suspensions were stored in polypropylene containers at $4{ }^{\circ} \mathrm{C}$ for further use. Goethite purity was confirmed by X-ray diffraction (XRD) with a PANalytical X'Pert Pro X-ray diffractometer with $\mathrm{Cu}$ Ka radiation $(c=1.5406 \AA)$ at $2 \theta$ range $=10-65^{\circ}$ (Figure S1).The B.E.T. specific surface area of the synthetic goethite $\left(89.6 \mathrm{~m}^{2} / \mathrm{g}\right)$ was determined on a Micromeritics AutoPore IV 9500 surface area analyzer, and was calculated from 90-point adsorption/desorption $\mathrm{N}_{2}(\mathrm{~g})$ isotherms before degassing overnight at $105^{\circ} \mathrm{C}$ under a stream of dry $\mathrm{N}_{2}(\mathrm{~g})$.

Leonardite Humic Acid Standard $(1 \mathrm{~S} 104 \mathrm{H})$ was purchased from the International Humic Substance Society. A LHA stock solution ( $2 \mathrm{~g} / \mathrm{L}, 1276 \mathrm{mg} \mathrm{C} / \mathrm{L})$ was prepared by dissolving $2 \mathrm{~g}$ LHA in $100 \mathrm{~mL}$ of $1 \mathrm{M}$ $\mathrm{NaOH}$, then diluted to $1 \mathrm{~L}$ with ultrapure water.

\subsection{NOM batch adsorption experiments}

All NOM adsorption experiments were conducted in the absence of background electrolyte ions, and under an atmosphere of humidified $\mathrm{N}_{2}(\mathrm{~g})$. This minimized any competitive adsorption reactions that would occur under dry conditions.

A $320 \mu \mathrm{L}$ aliquot of a goethite $\left(24.80 \mathrm{~g} / \mathrm{L}\right.$, specific surface area: $\left.89.6 \mathrm{~m}^{2} / \mathrm{g}\right)$ aqueous suspension was mixed with $19.6 \mathrm{~mL}$ diluted LHA solutions ( 1.276 to $1276 \mathrm{mg} \mathrm{C} / \mathrm{L}$ ) in $50 \mathrm{~mL}$ polyethylene centrifuge tubes to achieve $\mathrm{C} / \mathrm{Fe}(\mathrm{w} / \mathrm{w})$ ratios in the $0.005-5$ range. The suspensions were then adjusted to $\mathrm{pH} 5.0$ with a $\mathrm{pH}$ meter by addition of small volumes of $1.0 \mathrm{M} \mathrm{HCl}$ or $\mathrm{NaOH}$ and equilibrated on an end-to-end rotator at $25 \pm 1{ }^{\circ} \mathrm{C}$ for $48 \mathrm{~h}$. Next, the suspension was centrifuged at $\sim 2000 \mathrm{~g}$ for $15 \mathrm{~min}$, the supernatants were filtered $(0.2 \mu \mathrm{m})$ and 
the final soluble $\mathrm{C}$ concentrations were analyzed using a TOC analyzer (Shimadzu TOC-VCSH). The centrifuged wet pastes were analyzed by FTIR as described in Section 2.3.

\subsection{Dynamic Vapor Sorption}

The Dynamic Vapor Sorption (DVS) technique was used to trigger water vapor binding on initially dry LHA-goethite assemblages. Water binding was monitored in two sets of independent experiments using (1) Fourier Transform InfraRed (FTIR) spectroscopy, and (2) gravimetry by Quartz Crystal Microbalance (QCM).

For both experiments, water vapor was generated by mixing humid $\mathrm{N}_{2}(g)$ and dry $\mathrm{N}_{2}(\mathrm{~g})$ in different proportions using mass flow controllers (MKS, 179A). The total flow rate was always 200 standard cubic centimeters per minute $(\mathrm{sccm})$, and water vapor pressures were continuously measured using a Non Dispersible InfraRed device (LI-7000, Licor Inc). Preliminary FTIR and QCM experiments demonstrated that a 30 min equilibration period under a constant water vapor pressure was well sufficient to achieve equilibrium with respect to water vapor binding on the LHA-goethite assemblages.

\subsubsection{FTIR}

Centrifuged wet pastes were transferred onto a diamond window of an Attenuated Total Reflectance (ATR) cell (Golden Gate, single-bounce) and dried in the analytical chamber of a FTIR spectrometer under a flow of $200 \mathrm{sccm}$ dry $\mathrm{N}_{2}$ (g). FTIR spectra were collected during the drying period until all $\mathrm{O}-\mathrm{H}$ stretching and bending modes of free water disappeared. DVS experiments were then carried out on the resulting dry mineral film in a closed-loop flow-through reaction cell, and exposed to water vapor pressures from 0 to 19 Torr ( $80 \%$ R.H.) at $25 \pm 1{ }^{\circ} \mathrm{C}$.

FTIR spectra were continuously collected in situ with a Bruker Vertex 70/V FTIR spectrometer, equipped with a DLaTGS detector. All spectra were collected in the $600-4000 \mathrm{~cm}^{-1}$ range at a resolution of $4.0 \mathrm{~cm}^{-1}$ and at a forward/reverse scanning rate of $10 \mathrm{~Hz}$. Each spectrum was an average of 250 scans. The BlackmanHarris 3-term apodization function was used to correct phase resolution. 


\subsubsection{QCM}

A gold-coated quartz resonator operating at $10 \mathrm{MHz}$ was used for QCM measurements (eQCM 10M, Gamry Instruments Inc.). The time-independent serial resonance frequency $\left(f_{s}\right)$ of the quartz resonator exposed to a flow of $200 \mathrm{sccm}$ dry $\mathrm{N}_{2}$ (g) was first measured to obtain the correct baseline of the empty cell. A dilute aqueous suspension of the LHA-goethite assemblage was pipetted on the gold area of the resonator, then dried under the same flow of $\mathrm{N}_{2}(\mathrm{~g})$. The resulting $f_{s}$ was used to obtain the mass of the dry sample. A DVS experiment was then initiated to expose the sample to water vapor pressures from 0 to 19 Torr.

Changes in frequency $(\Delta \mathrm{f})$ of the quartz resonator were converted to changes in sample mass $(\Delta \mathrm{m})$ using the Sauerbrey equation: ${ }^{29}$

$$
\Delta f=-\frac{2 f_{0}^{2}}{A \sqrt{\rho_{q} \mu_{q}}} \Delta m
$$

In this equation $f_{0}$ is the resonant frequency of empty cell, $A$ is the piezoelectrically active crystal area of the gold-coated quartz crystal $\left(0.205 \mathrm{~cm}^{2}\right), \rho_{\mathrm{q}}$ is the density quartz $\left(2.648 \mathrm{~g} / \mathrm{cm}^{3}\right)$ and $\mu_{\mathrm{q}}$ is shear modulus of quartz $\left(2.947 \times 10^{11} \mathrm{~g} / \mathrm{cm} \cdot \mathrm{s}^{2}\right)$.

\subsubsection{Water Vapor Adsorption and Condensation Modeling}

Water vapor uptake by goethite and LHA sites was modeled using an adaptation of the model of Do \& Do $^{30}$, which we had previously ${ }^{31}$ shown to account for $(i)$ adsorption and (ii) and condensation phenomena in mineral powders:

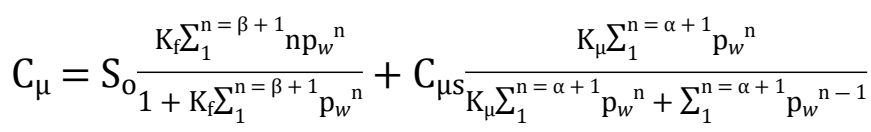

This equation predicts the total water condensation $\left(C_{\mu}\right)$ as a function of the reduced partial pressure of water $\left(\mathrm{p}_{\mathrm{w}}=\mathrm{p} / \mathrm{p}_{\mathrm{sat}} ;\right.$ where $\mathrm{p}_{\mathrm{sat}}$ is the saturation pressure) in terms of the aforementioned adsorption (left-hand term) and condensation (right-hand term) regimes. Parameters for each regime include water-binding site densities for adsorption $\left(\mathrm{S}_{\mathrm{o}}\right)$ and condensation $\left(\mathrm{C}_{\mu \mathrm{s}}\right)$ with their respective association constants $\left(\mathrm{K}_{\mathrm{f}}, \mathrm{K}_{\mu}\right)$ and hydration numbers $(\beta, \alpha)$. 
The adsorption term accounts for hydrogen binding of water molecules onto mineral and LHA surface

169 sites. It is B.E.T.-type equation ${ }^{32}$ which is however forced to plateau at $p_{w} \rightarrow 0$ by setting $\beta=2$. This value 170 denotes that a (hydr)oxo group can be involved in 2 (donating and/or accepting) hydrogen bonds, which is 171 average hydration number that we retrieved in previous molecular modeling of water adsorption on various 172 metal (oxy)hydroxides. ${ }^{31}$ The condensation pertains, in turn, to the condensation of water in the nano-/micro173 porous environments of the mineral-LHA mixture. It is triggered only when a nominal population of water 174 (nano)clusters (e.g. $\alpha=8)$ is exceeded ${ }^{30}$. While the data on hand could not be used to unambiguously constrain 175 condensation parameters of Eq. 2, the shape of the modelled curve nonetheless provide the possibility to 176 extract the adsorption term, which is central for understanding the intrinsic affinity of water to LHA-bound 177 goethite. Finally, we also used this equation to decompose the adsorption isotherm of LHA on goethite. 


\section{RESULTS AND DISCUSSIONS}

LHA binding at goethite surfaces follows a Type $\mathrm{II}^{33}$ adsorption isotherm loading (Figure 1), that can be characterized as an adsorption regime at low LHA concentrations, and a precipitation-like regime at high LHA. Maximal adsorption values under the adsorption regime are the equivalent of $\sim 56 \mathrm{C}$ atoms $/ \mathrm{nm}^{2}$, or $\sim 3.7$ times the total crystallographic oxygen site density $\left(\sim 15 \text { sites } / \mathrm{nm}^{2}\right)^{27,34,35}$. From these results, we estimate that the goethite surface should be already covered in LHA at total $\mathrm{C} / \mathrm{Fe}>0.05$. The highest $\mathrm{LHA}$ loadings $(\mathrm{C} / \mathrm{Fe}=5$; 220 adsorbed $\mathrm{C}$ atoms $/ \mathrm{nm}^{2}$ ) suggest a precipitation-like regime possibly triggered by LHA-LHA interactions, and therefore in the establishment of LHA bulk environments entirely covering the goethite surface.

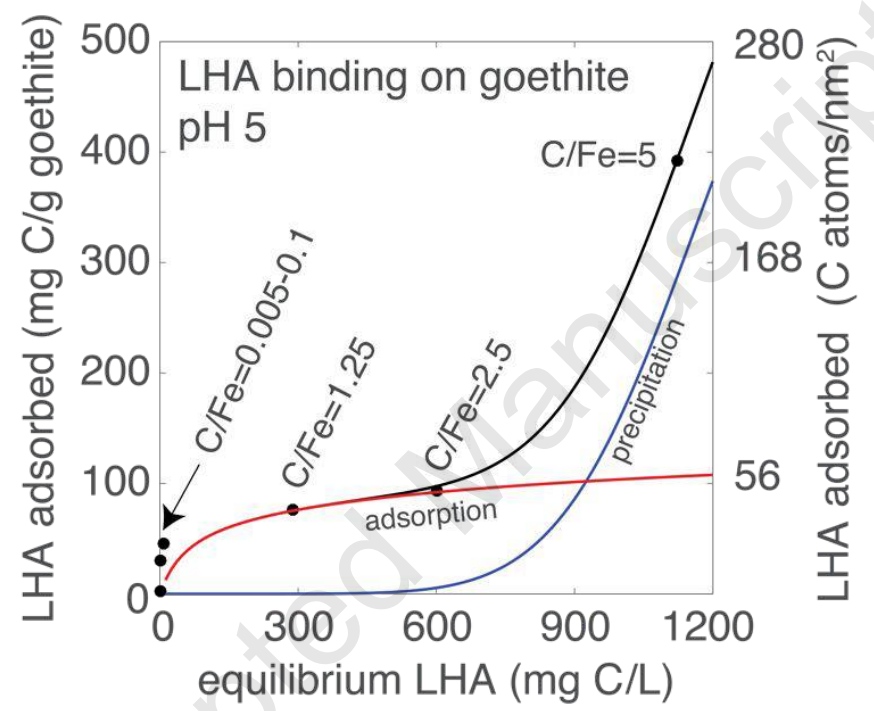

192

Figure 1. LHA binding on goethite after equilibration at $\mathrm{pH} 5$. Total $\mathrm{C} / \mathrm{Fe}$ ratios are expressed in terms of adsorption and precipitated LHA. The model was generated using Eq.2, here adapted for the case of LHA binding and precipitation on goethite.

Water vapor binding on goethite follows the characteristics of Type $\mathrm{II}^{33}$ adsorption isotherms, and is strongly affected by LHA loadings (Figures $2 \mathrm{a}-\mathrm{b}$ ). LHA loadings in the $\mathrm{C} / \mathrm{Fe}=0.005-0.01$ range decreased goethite hydrophilicity, while loadings above this this range increased hydrophilicity. Water uptake of unbound LHA is highest due to its heterogeneous structure and abundant hydrophilic functional groups. As a result, increasing excess LHA loadings promotes water uptake. 
These changes can be appreciated further by decomposing these adsorption isotherms in terms of $(i)$ adsorption and (ii) condensation regimes (Figure 2a), using Do \& Do ${ }^{30}$ theory (Eq. 2) presented in Section 2.3.3. In this framework, adsorption pertains to the attachment of water molecules to mineral surface and LHA functional groups via hydrogen bonding, followed by growth in the neighborhood of the adsorption site, very much in the manner described by B.E.T. theory. ${ }^{32}$ Condensation, on the other hand, pertains to water-water interactions leading to growth and coalescence of water (nano)droplets in (nano)/(micro)pores between goethite particles and within the LHA bulk..$^{33}$

Modeling of the water adsorption isotherms shows that maximal densities achieved under the adsorption regime on LHA-free goethite are equivalent to the total crystallographic $O$ surface density $(\sim 15$ $\left.\mathrm{H}_{2} \mathrm{O} / \mathrm{nm}^{2}\right)^{27,31,32}$, and therefore $\sim 1-1.5 \mathrm{H}_{2} \mathrm{O}$ monolayers. These loadings are however strongly affected by LHA loadings, as shown by the relationship of Figure 2c. This correlation expresses the decreased hydrophilicity of goethite at $\mathrm{C} / \mathrm{Fe}$ below $\sim 0.24$ and of the increased hydrophilicity above these loadings. A mechanistic interpretation of these results can be developed by understanding the nature of organic-mineral interactions, and of hydrogen bonding of water on LHA-coated goethite. This can be gained by following the changes in the availability of the hydrophilic hydroxyl functional groups on goethite, as well as those of LHA (Figure 3), as will be detailed in the following paragraphs.

a)

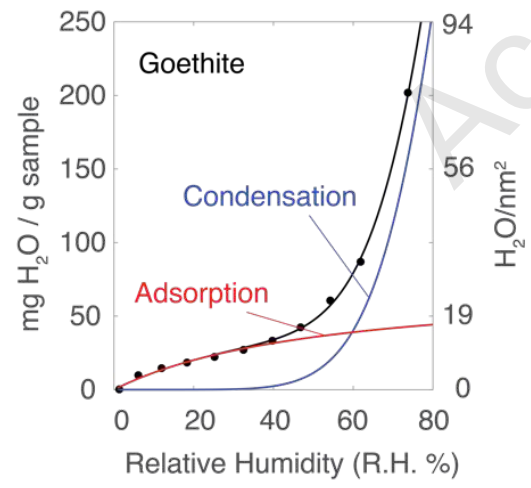

b)

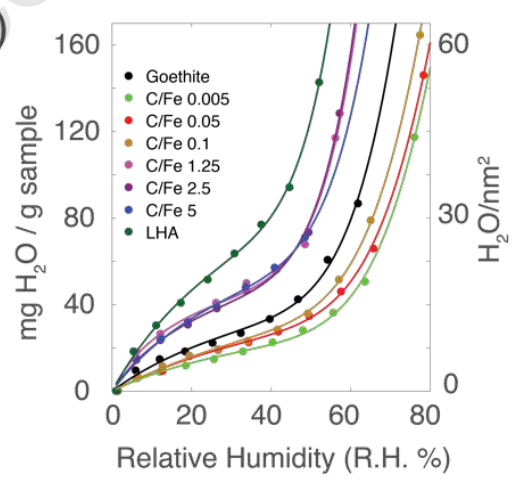

c)

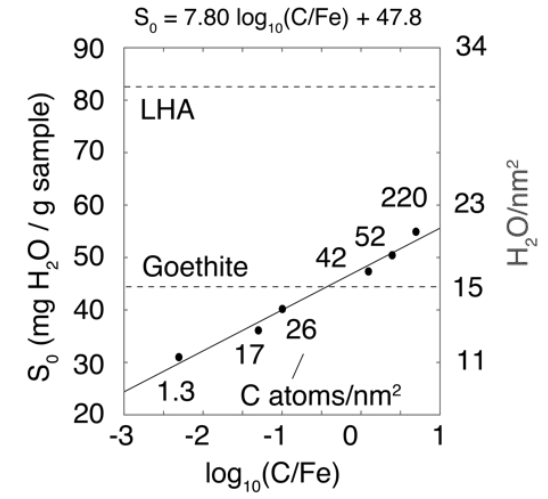

Figure 2. QCM-derived masses of water uptake by LHA and goethite. (a) Typical Type II water sorption isotherm on pure goethite. (b) Sorption isotherms for pure goethite, LHA and goethite-LHA, reported as total C/Fe (w/w). (c) Relationship between water site density ( $\mathrm{S}_{0}$ of Eq. 2$)$ and total carbon loading on goethite $(\mathrm{C} / \mathrm{Fe})$. Values for pure goethite and LHA are shown for reference. 

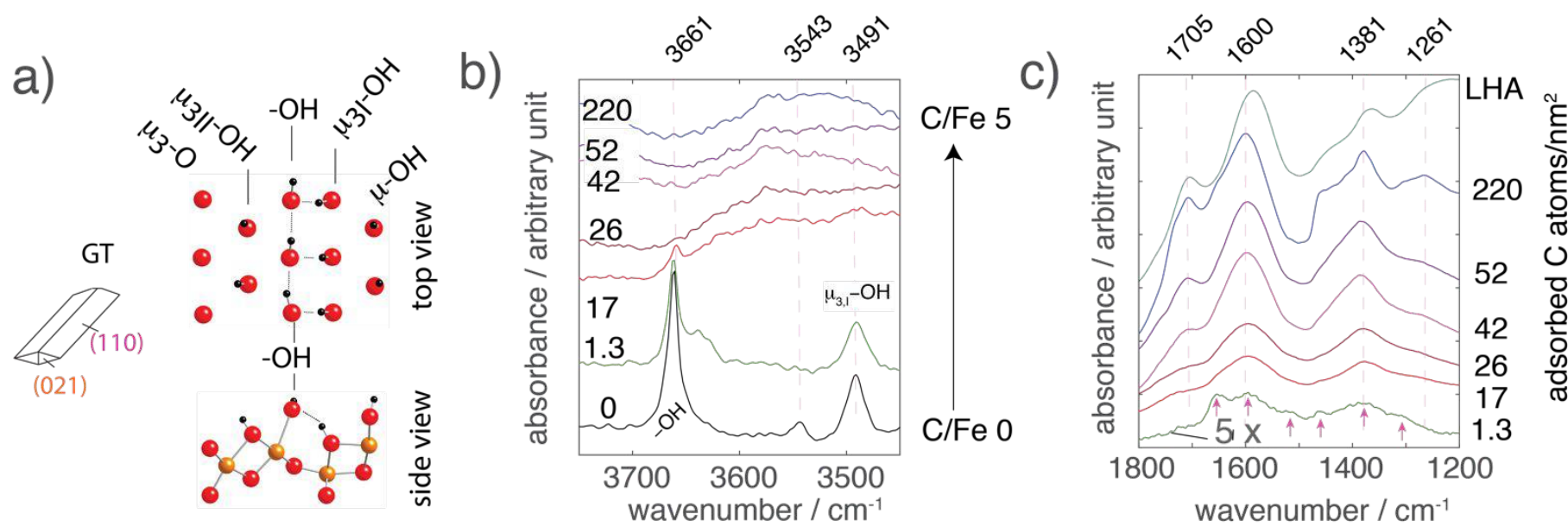

Figure 3. (a). Schematic representation of crystal habits of goethite (GT) particles under study, obtained from a selected portion of a snapshot of a Molecular Dynamics simulation from a previous study. ${ }^{18}$ (b-c) FTIR spectra of LHA-Goethite samples equilibrated at $\mathrm{pH} 5$ then dried under $\mathrm{N}_{2}(\mathrm{~g})$. (c) Difference spectra of the 1200-1800 $\mathrm{cm}^{-1}$ region, with removed contributions from the goethite bulk $\left(\delta_{\mathrm{OH}^{+}} \gamma_{\mathrm{OH}}=1659 \mathrm{~cm}^{-1} ; \delta^{\prime}{ }_{\mathrm{OH}}=1794 \mathrm{~cm}^{-1} ; c f\right.$. Figure $\mathrm{S} 1$ for raw data). Arrows in 1.3 adsorbed $\mathrm{C}$ atoms $/ \mathrm{nm}^{2}$ point to collection of bands.

Changes in the availability of hydrophilic hydroxo groups populating the goethite surface (Fig. 3a) can be revealed by vibrational spectroscopy (Fig. 3b), a detailed account of which is given in a series of articles from our group. ${ }^{17-19,22,36,37}$ Briefly, the dominant (110) crystallographic face of goethite populated by rows of singly-coordinated $-\mathrm{OH}$, doubly-coordinated $\mu-\mathrm{OH}$, and triply-coordinated $\mu_{3}-\mathrm{OH}$ groups. About $50 \%$ of these $-\mathrm{OH}$ donate a hydrogen bond to a neighboring $-\mathrm{OH}$, while all accept a hydrogen bond from an underlying $\mu_{3, \mathrm{I}}-\mathrm{OH}$, as in the goethite bulk. ${ }^{17-19,22,36,37}$ The intensities and positions of $\mathrm{O}-\mathrm{H}$ stretching bands of $-\mathrm{OH}$ groups $\left(3661 \mathrm{~cm}^{-1}\right)$ and of the less reactive $\mu-\mathrm{OH}$ and $\mu_{3, \mathrm{I}}-\mathrm{OH}$ groups $\left(3648 \mathrm{~cm}^{-1}\right)$ are especially sensitive indicators of ligand exchange and hydrogen bonding reactions. Variations in the intensities of the triply-coordinated $\mu_{3, \mathrm{I}}-\mathrm{OH}$ sites $\left(3491 \mathrm{~cm}^{-1}\right)$ are, in turn, a direct response of the coordination changes in $-\mathrm{OH}$ due to the presence of a hydrogen bond between these two groups $\left(\mu_{3, \mathrm{I}}-\mathrm{OH} \cdots \mathrm{OH}^{-}\right)$. Finally, we note that while the minor (021) face also exposes $-\mathrm{OH}$ and $\mu-\mathrm{OH}$ groups they are so strongly hydrogen-bonded that they generate no resolvable O-H stretch, as described in Song and Boily. ${ }^{17}$

The loss in intensity of these $\mathrm{O}-\mathrm{H}$ stretching bands in the $\mathrm{C} / \mathrm{Fe} 0-0.1$ range confirms the loss of hydrophilic $-\mathrm{OH}$ groups via ligand exchanges and/or the loss of the hydrophilic activity of these groups via hydrogen bonding with LHA functional groups. ${ }^{25,37-39}$ These changes correlate with the appearance of LHA functional groups in the range of $1200-1800 \mathrm{~cm}^{-1}$ (Figure $3 \mathrm{c}$ ), which we interpret as the appearance of a mixture of protonated $\left(v_{\mathrm{C}=\mathrm{O} \text { carboxyl }}=1705 \mathrm{~cm}^{-1}, v_{\mathrm{C}-\mathrm{O}-\mathrm{H}}=1261 \mathrm{~cm}^{-1}\right)$ and deprotonated $\left(v_{\mathrm{COOs}}=1381 \mathrm{~cm}^{-1}\right)$ groups, as well as aromatic backbone of LHA $\left(v_{\mathrm{C}=\mathrm{C}}\right.$ aromatic $\left.=1600 \mathrm{~cm}^{-1}\right)$. They also reveal that the LHA-reacted 
goethite surface exposes a mixture of $-\mathrm{OH}$ groups and of LHA. At C loadings greater than the crystallographic density of goethite surface oxygens $\left(>26 \mathrm{C}\right.$ atoms $\left./ \mathrm{nm}^{2} ; \mathrm{C} / \mathrm{Fe}>0.1\right)$, all intensities of the $-\mathrm{OH}$ band are lost due to direct ligand exchange with LHA and a red-shift in the stretching frequency of hydrogen-bonded group to a broad range of values below $3661 \mathrm{~cm}^{-1}$. The $\mathrm{O}-\mathrm{H}$ spectral signature is then characterized by a blue-shift in the band of $\mu_{3, I}-\mathrm{OH}$ from the weakening of its hydrogen bond with $-\mathrm{OH}$, as well as from the appearance of $\mathrm{OH}$ groups of sorbed LHA. Additionally, because LHA loadings increased under conditions where all -OH groups have been occupied, LHA binding must have been driven by additional mechanisms such as van der Waals-type hydrophobic bonding. This mechanism could be responsible for the precipitation of LHA at the highest loadings considered in this work (Fig. 1).
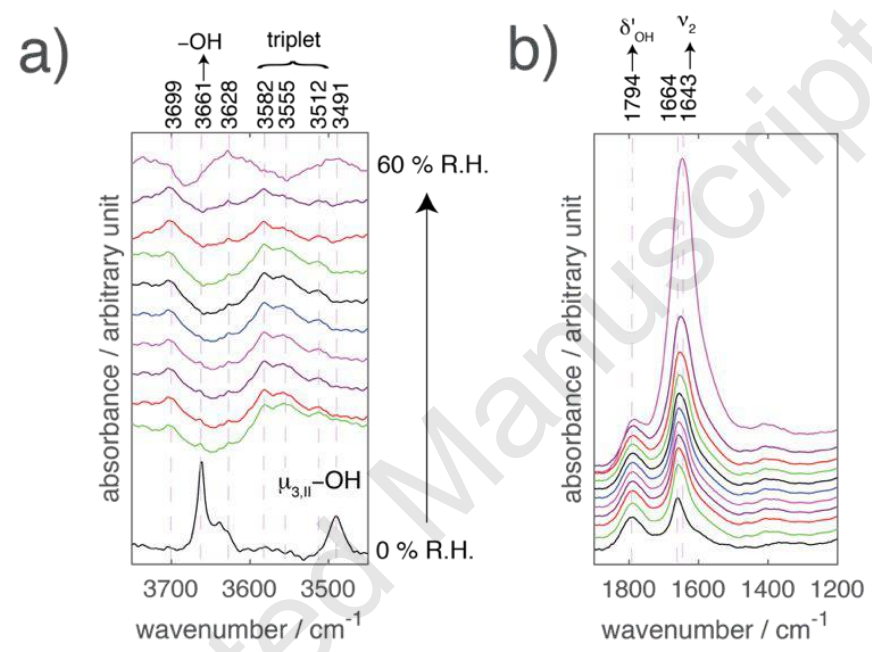

Figure 4. Baseline-subtracted FTIR spectra of $\mathrm{C} / \mathrm{Fe}=0.005$ exposed to $0-60 \%$ R.H. (a) O-H stretching region responding to $-\mathrm{OH}$ and $\mu_{31} \mathrm{OH}$ groups. The $3699 \mathrm{~cm}^{-1}$ band is likely from geminal water bound directly to Fe sites, but is outside the scope of this work. (b) The 1200-1900 $\mathrm{cm}^{-1}$ region. This region shows the appearance of liquid-like water through the growth of the bending band of water $\left(v_{2}\right)$. The $\delta{ }^{\prime}{ }_{\mathrm{OH}} 1794 \mathrm{~cm}^{-1}$ band is an bending overtone of the goethite bulk, and therefore not affected by water binding.

a)

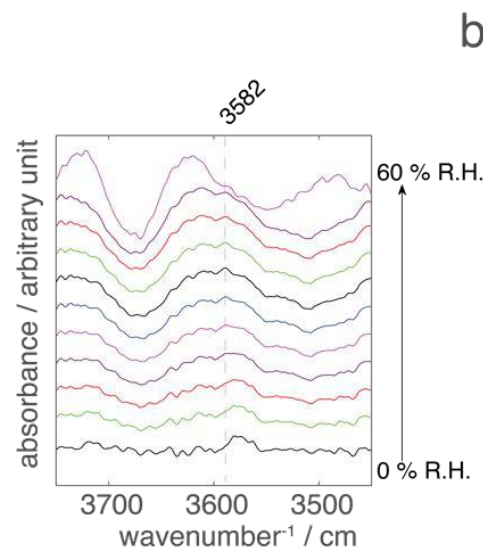

b)

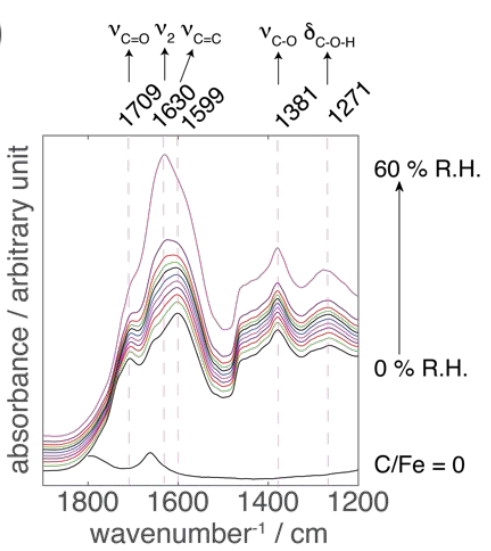

c)

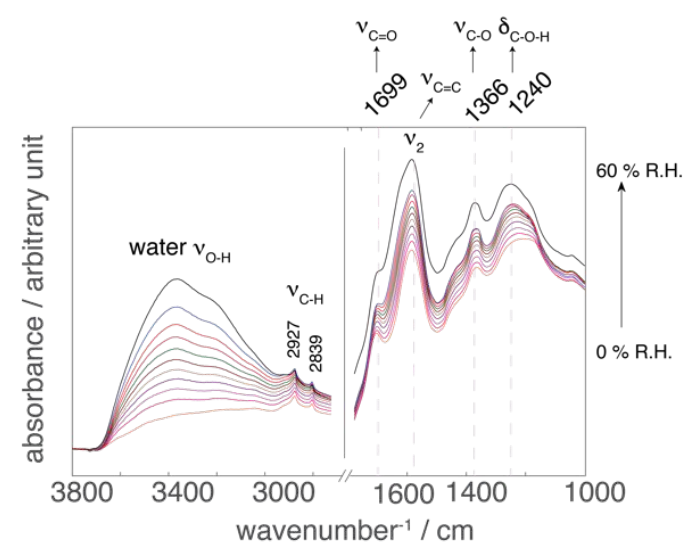

Figure 5. (a-b) Baseline-subtracted FTIR spectra of $\mathrm{C} / \mathrm{Fe}=5$ exposed to $0-60 \%$ R.H. (c) FTIR spectra of LHA first equilibrated at $\mathrm{pH} 5$, then exposed to water vapor. 
Exposure of water vapor to LHA-coated goethite (Fig. 4 \& 5) also induced systematic changes in the vibration spectra of goethite and LHA functional groups, and generated bands strongly indicative of the formation of liquid-like water. ${ }^{41,42}$ While this can first be appreciated by the appearance of the bending $\left(v_{2}\right.$; Fig. 4b) and of the broad O-H stretching (Fig. 5c) bands of water deposited within the three-dimensional framework of LHA (see also Figs S3 \& S4), the spectral signature of hydrophilic OH groups provide greater details on water condensation mechanisms.

Samples with the lowest LHA loadings $(\mathrm{C} / \mathrm{Fe}=0.005)$ provide insight into the mechanisms of water binding at goethite surfaces exposing a mixture of $(i)$ non-reacted -OH groups and (ii) adjacently-bound LHA molecules. While our results (Fig. 2) showed that water loadings were lower than on LHA-free goethite, vibration spectra (Fig. 4) suggest that water binding mechanisms were not altered by LHA-binding. ${ }^{18}$ This can be appreciated in the loss and red-shift of the $3661 \mathrm{~cm}^{-1}$ band of $-\mathrm{OH}$ with water loading, as well as in the blue-shift of the $3490 \mathrm{~cm}^{-1}$ band of $\mu_{3, \mathrm{I}}-\mathrm{OH}$ to a triplet at 3512,3555 , and $3582 \mathrm{~cm}^{-1}$, also seen in LHA-free goethite. ${ }^{18}$ We note that this triplet results from a weakening of the $\mathrm{H}$-bonding strength between $\mu_{3, \mathrm{I}}-\mathrm{OH}$ and $-\mathrm{OH}$ sites by water through the formation of hydrogen bonding networks of the type: $\mu_{3, \mathrm{I}}-\mathrm{OH} \cdots-\mathrm{OH}^{\cdots}-\mathrm{OH}_{2}$ and/or $\mu_{3,-}-\mathrm{OH}^{\cdots}-\mathrm{OH}_{2}$. As water-binding mechanisms remain unchanged by LHA, lower water loadings are likely to result from the consumption of hydrophilic sites by LHA surface complexation, for example via ligand exchange and/or hydrogen bonding. This could also imply that the intrinsic LHA bulk structure (e.g., intramolecular hydrogen bonding network) has undergone changes that, for example, expose hydrophobic sites to the outer portion of the macromolecules. This concept can be supported further in the $1200-1800 \mathrm{~cm}^{-}$ ${ }^{1}$ region (Fig. 3c) revealing a combination of bands that is not manifested at larger LHA loadings. Previous work from our group even showed that these conformational changes could be responsible for increasing the thermal stability of mineral-bound NOM.

This scenario diverges starkly with water binding to samples of high $\mathrm{C} / \mathrm{Fe}$ loadings which, again, promote greater water loadings than in LHA-free goethite (Fig. 2). In this case, the aforementioned triplet (Fig. 4a) is readily transformed to a broad singlet, which is characteristic of a broad distribution of hydrogen bonding environments (Fig. 5a). We also note that the water vapor pressure dependence of the $1200-1800 \mathrm{~cm}^{-1}$ region 
is also considerably less sensitive than that of pure LHA (Fig. 5). This suggests that LHA functional groups directly bound to goethite remain largely unaffected by hydration. It also implies that while water condensation in the three-dimensional array of pure LHA facilitates high water loadings, LHA binding to goethite limits this intrinsic capability to accommodate water.

To summarize, we can explain the strong LHA-loading dependence on water binding in the following manner. LHA binding at low loadings $\left(1.3-26 \mathrm{C}\right.$ atoms $\left./ \mathrm{nm}^{2} ; \mathrm{C} / \mathrm{Fe}=0.005-0.1\right)$ involves a greater proportion of LHA moieties for ligand exchange or hydrogen bonding to goethite surfaces. This results in potentially important configurational changes in LHA structure, perhaps even exposing hydrophobic portions of the molecule to the goethite surface. This, with the decrease in accessible hydrophilic groups of the goethite surface, collectively lowers water binding on goethite reacted LHA loadings below $\sim 240 \mathrm{mg}$ C per g Fe. Water affinities become, in turn, substantially larger at high $\mathrm{C} / \mathrm{Fe}$ loadings because a smaller fraction of the moieties is dedicated to binding with goethite, leaving excess LHA reacting with water in a similar manner to pure LHA.

Finally, we note that while this work on water condensation in NOM-reacted minerals was limited to a model system, we anticipate that its findings should be applicable to a wider range of representative systems. Recognition of the NOM loading dependency on the hygroscopic properties of solid materials in nature should not only be of importance to the study of terrestrial environments but also in the study of atmospheric clouds and rain formation phenomena ${ }^{43,44}$ Additionally, the molecular-scale knowledge of water vapor binding in organic-mineral assemblages should serve to consolidate our understanding of natural photocatalytic reactions ${ }^{45}$ where co-adsorbed water is an essential ingredient in photodegradation processes. ${ }^{46}$ 


\section{ACKNOWLEDGEMENTS}

This work was supported by the Swedish Research Council through a grant to J.-F.B. (2016-03808). We thank the China Scholarship Council for a Ph.D. grant and Rennes Métropole (France) for a mobility grant for an extended research visit at Umeå University.

\section{REFERENCES}

(1) Matějková, š.; Šimon, T. Application of FTIR Spectroscopy for Evaluation of Hydrophobic/Hydrophilic Organic Components in Arable Soil. Plant Soil Environ. 2012, 58 (No. 4), 192-195. https://doi.org/10.17221/317/2011-PSE.

(2) Nebbioso, A.; Piccolo, A. Molecular Characterization of Dissolved Organic Matter (DOM): A Critical Review. Anal. Bioanal. Chem. 2013, 405 (1), 109-124. https://doi.org/10.1007/s00216-012-6363-2.

(3) Piccolo, A. The Nature of Soil Organic Matter and Innovative Soil Managements to Fight Global Changes and Maintain Agricultural Productivity. Carbon Sequestration Agric. Soils Multidiscip. Approach Innov. Methods 2012. https://doi.org/10.1007/978-3-642-23385-2_1.

(4) Perminova, I. V.; Frimmel, F. H.; Kudryavtsev, A. V.; Kulikova, N. A.; Abbt-Braun, G.; Hesse, S.; Petrosyan, V. S. Molecular Weight Characteristics of Humic Substances from Different Environments As Determined by Size Exclusion Chromatography and Their Statistical Evaluation. Environ. Sci. Technol. 2003, 37 (11), 2477-2485. https://doi.org/10.1021/es0258069.

(5) Vindedahl, A. M.; Stemig, M. S.; Arnold, W. A.; Penn, R. L. Character of Humic Substances as a Predictor for Goethite Nanoparticle Reactivity and Aggregation. Environ. Sci. Technol. 2016, 50 (3), 1200-1208. https://doi.org/10.1021/acs.est.5b04136.

(6) Kaiser, K.; Guggenberger, G. Mineral Surfaces and Soil Organic Matter. Eur. J. Soil Sci. 54 (2), 219 236. https://doi.org/10.1046/j.1365-2389.2003.00544.x.

(7) Chassé, A. W.; Ohno, T.; Higgins, S. R.; Amirbahman, A.; Yildirim, N.; Parr, T. B. Chemical Force Spectroscopy Evidence Supporting the Layer-by-Layer Model of Organic Matter Binding to Iron (Oxy)Hydroxide Mineral Surfaces. Environ. Sci. Technol. 2015, 49 (16), 9733-9741. https://doi.org/10.1021/acs.est.5b01877.

(8) Philippe, A.; Schaumann, G. E. Interactions of Dissolved Organic Matter with Natural and Engineered Inorganic Colloids: A Review. Environ. Sci. Technol. 2014, 48 (16), 8946-8962. https://doi.org/10.1021/es502342r.

(9) Chi, F.-H.; Amy, G. L. Kinetic Study on the Sorption of Dissolved Natural Organic Matter onto Different Aquifer Materials: The Effects of Hydrophobicity and Functional Groups. J. Colloid Interface Sci. 2004, 274 (2), 380-391. https://doi.org/10.1016/j.jcis.2003.12.049.

(10) Smith, K. E. C.; Thullner, M.; Wick, L. Y.; Harms, H. Dissolved Organic Carbon Enhances the Mass Transfer of Hydrophobic Organic Compounds from Nonaqueous Phase Liquids (NAPLs) into the Aqueous Phase. Environ.Sci.Technol. 2011, 45 (20), 8741-8747. https://doi.org/10.1021/es202983k.

(11) Situm, A.; Rahman, M. A.; Allen, N.; Kabengi, N.; Al-Abadleh, H. A. ATR-FTIR and Flow Microcalorimetry Studies on the Initial Binding Kinetics of Arsenicals at the Organic-Hematite Interface. L.Phvs. Chem.A 2017, 121 (30), 5569-5579. https://doi.org/10.1021/acs.jpca.7b03426. 
(12) Strathmann, T. J.; Stone, A. T. Reduction of Oxamyl and Related Pesticides by FeII: Influence of Organic Ligands and Natural Organic Matter. Environ.S_. Sci.Technol. 2002, 36 (23), 5172-5183. https://doi.org/10.1021/es0205939.

(13) Iglesias, A.; López, R.; Gondar, D.; Antelo, J.; Fiol, S.; Arce, F. Adsorption of Paraquat on Goethite and Humic Acid-Coated Goethite. J.Hazard. Mater. 2010, 183 (1), 664-668. https://doi.org/10.1016/j.jhazmat.2010.07.077.

(14) Weng, L.; Van Riemsdijk, W. H.; Hiemstra, T. Cu2+ and Ca2+adsorption to Goethite in the Presence of Fulvic Acids. Geochim. Cosmochim. Acta 2008, $72 \quad$ (24), 5857-5870. https://doi.org/10.1016/j.gca.2008.09.015.

(15) Murphy, E. M.; Zachara, J. M.; Smith, S. C. Influence of Mineral-Bound Humic Substances on the Sorption of Hydrophobic Organic Compounds. Environ. Sci. Technol. 1990, 24 (10), 1507-1516. https://doi.org/10.1021/es00080a009.

(16) Capriel, P.; Beck, T.; Borchert, H.; Gronholz, J.; Zachmann, G. Hydrophobicity of the Organic Matter in Arable Soils. Soil Biol.Biochem. 1995, 27 (11), 1453-1458. https://doi.org/10.1016/00380717(95)00068-P.

(17) Song, X.; Boily, J.-F. Structural Controls on OH Site Availability and Reactivity at Iron Oxyhydroxide Particle Surfaces. Phvs. Chem. Chem. Phvs. 2012, 14 (8), 2579-2586. https://doi.org/10.1039/C2CP22715K.

(18) Song, X.; Boily, J.-F. Water Vapor Adsorption on Goethite. Environ. Sci.Technol. 2013, 47 (13), 71717177. https://doi.org/10.1021/es400147a.

(19) Song, X.; Boily, J.-F. Water Vapor Interactions with FeOOH Particle Surfaces. Chem. Phvs. Lett. 2013, 560, 1-9. https://doi.org/10.1016/j.cplett.2012.12.048.

(20) Feng, W.; Klaminder, J.; Boily, J.-F. Thermal Stability of Goethite-Bound Natural Organic Matter Is Impacted by Carbon Loading. L L Phvs. Chem. A 2015, 119 (51), 12790-12796. https://doi.org/10.1021/acs.jpca.5b09821.

(21) Boily, J.-F. Water Structure and Hydrogen Bonding at Goethite/Water Interfaces: Implications for Proton Affinities. L.Phvs. Chem.C 2012, 116 (7), 4714-4724. https://doi.org/10.1021/jp2110456.

(22) Boily, J.-F.; Szanyi, J.; Felmy, A. R. A Combined FTIR and TPD Study on the Bulk and Surface Dehydroxylation and Decarbonation of Synthetic Goethite. Geochim. Cosmochim. Acta 2006, 70 (14), 3613-3624. https://doi.org/10.1016/j.gca.2006.05.013.

(23) Hur, J.; Schlautman, M. A. Molecular Weight Fractionation of Humic Substances by Adsorption onto Minerals. L. Colloid Interface Sci. 2003, 264 (2), 313-321. https://doi.org/10.1016/S00219797(03)00444-2.

(24) Qin, X.; Liu, F.; Wang, G.; Hou, H.; Li, F.; Weng, L. Fractionation of Humic Acid upon Adsorption to Goethite: Batch and Column Studies. Chem. Eng J 2015, 269, 272-278. https://doi.org/10.1016/j.cej.2015.01.124.

(25) Kang, S.; Xing, B. Humic Acid Fractionation upon Sequential Adsorption onto Goethite. Langmuir 2008, 24 (6), 2525-2531. https://doi.org/10.1021/la702914q.

(26) M. Vindedahl, A.; H. Strehlau, J.; A. Arnold, W.; Lee Penn, R. Organic Matter and Iron Oxide Nanoparticles: Aggregation, Interactions, and Reactivity. Environ. Sci._Nano 2016, 3 (3), 494-505. https://doi.org/10.1039/C5EN00215J.

(27) Gaboriaud, F.; Ehrhardt, J.-J. Effects of Different Crystal Faces on the Surface Charge of Colloidal Goethite $(\alpha-\mathrm{FeOOH})$ Particles: An Experimental and Modeling Study. Geochim. Cosmochim. Acta 2003, 67 (5), 967-983. 
(28) Marsac, R.; Martin, S.; Boily, J.-F.; Hanna, K. Oxolinic Acid Binding at Goethite and Akaganéite Surfaces: Experimental Study and Modeling. Environ. Sci. Technol. 2016, 50 (2), 660-668. https://doi.org/10.1021/acs.est.5b04940.

(29) Sauerbrey, G. Verwendung von Schwingquarzen zur Wägung dünner Schichten und zur Mikrowägung. Z. Für Phvs. 1959, 155 (2), 206-222. https://doi.org/10.1007/BF01337937.

(30) Do, D. D.; Do, H. D. A Model for Water Adsorption in Activated Carbon. Carbon 2000, 38 (5), $767-$ 773. https://doi.org/10.1016/S0008-6223(99)00159-1.

(31) Yeşilbaş, M.; Boily, J.-F. Particle Size Controls on Water Adsorption and Condensation Regimes at Mineral Surfaces. Sci._Ren. 2016, 6, 32136. https://doi.org/10.1038/srep32136.

(32) Brunauer, S.; Emmett, P. H.; Teller, E. Adsorption of Gases in Multimolecular Layers. J. Am. Chem. Soc. 1938, 60 (2), 309-319. https://doi.org/10.1021/ja01269a023.

(33) Sing, K. S. W. Reporting Physisorption Data for Gas/Solid Systems with Special Reference to the Determination of Surface Area and Porosity (Recommendations 1984). Pure Appl. Chem. 1985, 57 (4), 603-619. https://doi.org/10.1351/pac198557040603.

(34) Hiemstra, T.; Van Riemsdijk, W. H. A Surface Structural Approach to Ion Adsorption: The Charge Distribution (CD) Model. L.Colloid Interface Sci. 1996, 179 (2), 488-508.

(35) Boily, J.-F.; Felmy, A. R. On the Protonation of Oxo- and Hydroxo-Groups of the Goethite $(\alpha-\mathrm{FeOOH})$ Surface: A FTIR Spectroscopic Investigation of Surface O-H Stretching Vibrations. Geochim. Cosmochim Acta 2008, 72 (14), 3338-3357. https://doi.org/10.1016/j.gca.2008.04.022.

(36) Ding, X.; Song, X.; Boily, J.-F. Identification of Fluoride and Phosphate Binding Sites at FeOOH Surfaces. L.Phvs.Chem.C 2012, 116 (41), 21939-21947. https://doi.org/10.1021/jp3083776.

(37) Kanematsu, M.; Waychunas, G. A.; Boily, J.-F. Silicate Binding and Precipitation on Iron Oxyhydroxides. Environ. Sci. Technol. 2018, 52 (4), 1827-1833. https://doi.org/10.1021/acs.est.7b04098.

(38) Gu, B.; Schmitt, J.; Chen, Z.; Liang, L.; McCarthy, J. F. Adsorption and Desorption of Different Organic Matter Fractions on Iron Oxide. Geochim. Cosmochim. Acta 1995, 59 (2), 219-229. https://doi.org/10.1016/0016-7037(94)00282-Q.

(39) Fu, H.; Quan, X. Complexes of Fulvic Acid on the Surface of Hematite, Goethite, and Akaganeite: FTIR Observation. Chemosphere 2006, $63 \quad$ (3), 403-410. https://doi.org/10.1016/j.chemosphere.2005.08.054.

(40) Gu, B.; Schmitt, J.; Chen, Z.; Liang, L.; McCarthy, J. F. Adsorption and Desorption of Natural Organic Matter on Iron Oxide: Mechanisms and Models. Environ. Sci. Technol. 1994, 28 (1), 38-46. https://doi.org/10.1021/es00050a007.

(41) Ghabbour, E. A.; Davies, G. Humic Substances: Structures, Models and Functions; Royal Society of Chemistry, 2007.

(42) Senesi, N.; Miano, T. M.; Provenzano, M. R.; Brunetti, G. Spectroscopic and Compositional Comparative Characterization of I.H.S.S. Reference and Standard Fulvic and Humic Acids of Various Origin. Sci.Total Environ. 1989, 81-82, 143-156. https://doi.org/10.1016/0048-9697(89)90120-4.

(43) Levin, Z.; Teller, A.; Ganor, E.; Yin, Y. On the Interactions of Mineral Dust, Sea-Salt Particles, and Clouds: A Measurement and Modeling Study from the Mediterranean Israeli Dust Experiment Campaign. J. Geophys. Res. Atmospheres 2005, $110 \quad$ (D20202), 1-19. https://doi.org/10.1029/2005JD005810.

(44) Noziere, B. Don't Forget the Surface. Science 2016, 351 (6280), 1396-1397. https://doi.org/10.1126/science.aaf3253. 
(45) Cwiertny, D. M.; Young, M. A.; Grassian, V. H. Chemistry and Photochemistry of Mineral Dust Aerosol. Annu. Rev. Phvs Chem. 2008, 59 (1), 27-51. https://doi.org/10.1146/annurev.physchem.59.032607.093630.

(46) Mino, L.; Zecchina, A.; Martra, G.; Rossi, A. M.; Spoto, G. A Surface Science Approach to TiO2 P25 Photocatalysis: An in Situ FTIR Study of Phenol Photodegradation at Controlled Water Coverages from Sub-Monolayer to Multilayer. Appl Catal $B$ Environ. 2016, 196, 135-141. https://doi.org/10.1016/j.apcatb.2016.05.029.

462

463

464

465

466

467

468

469

470

471

472

473

474

475

476

477

478

479

480

481

482

483

484

485

486

487

488

489

490

491

492

493

494 


\section{Graphical Abstract}

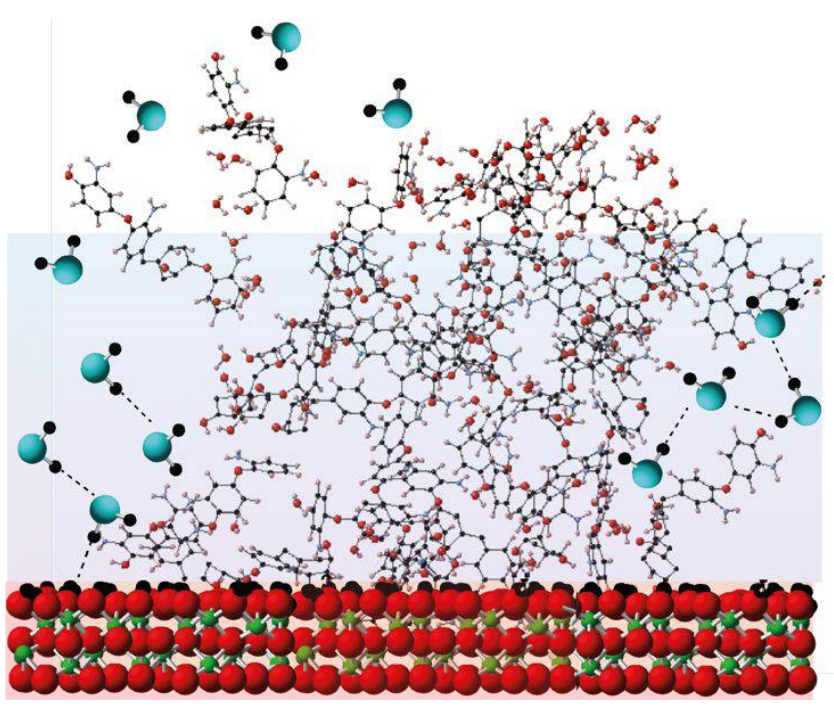




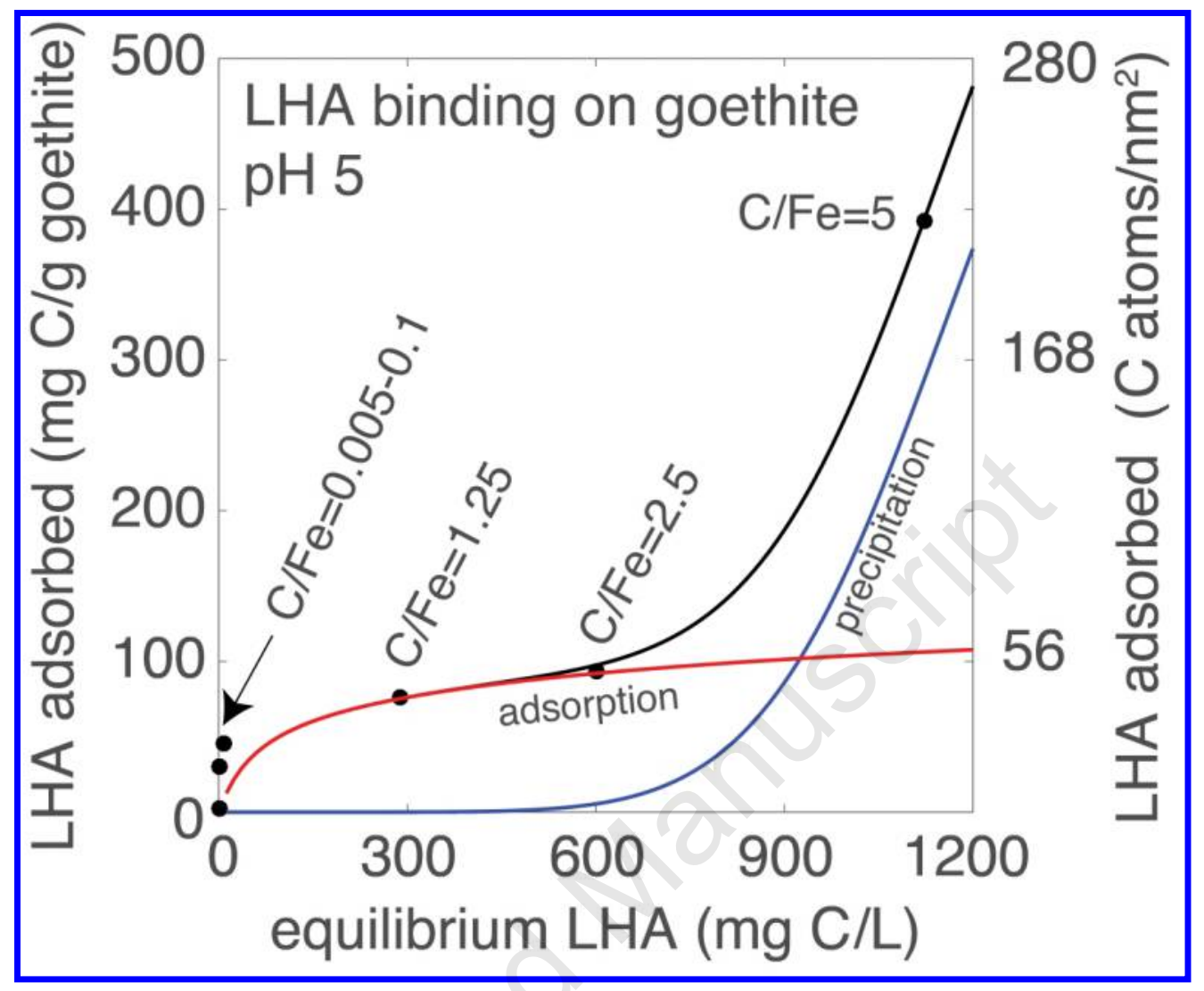




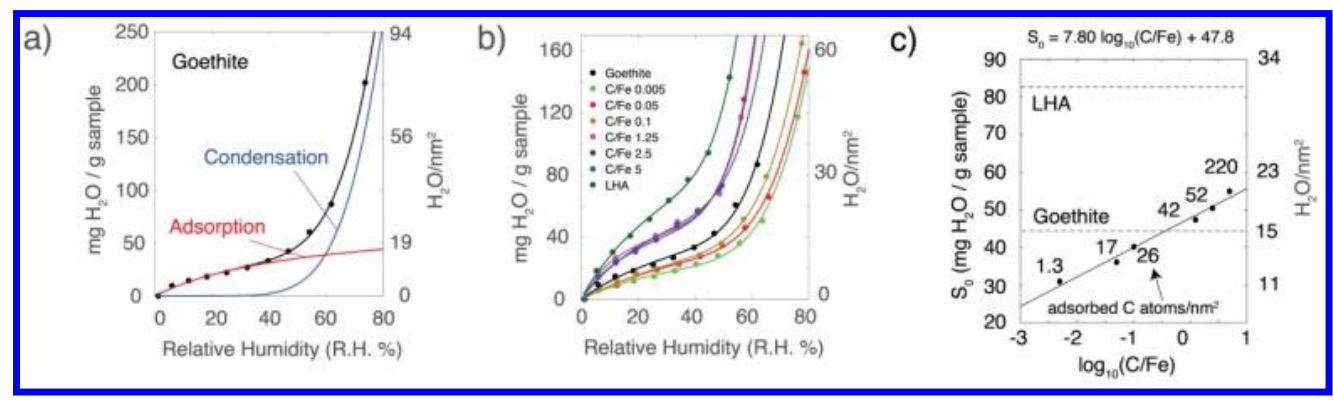




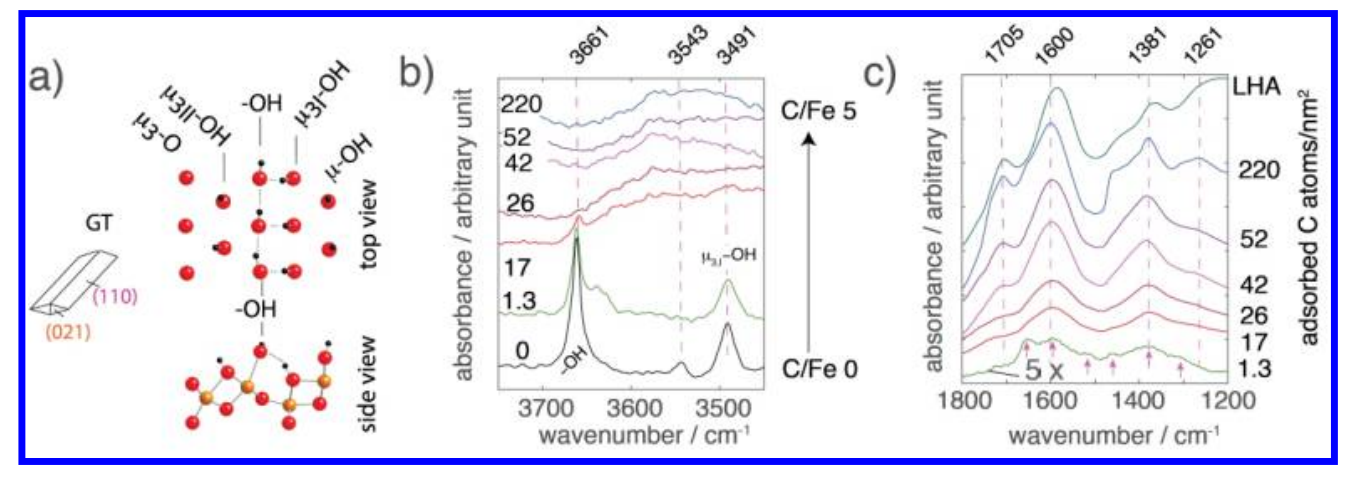




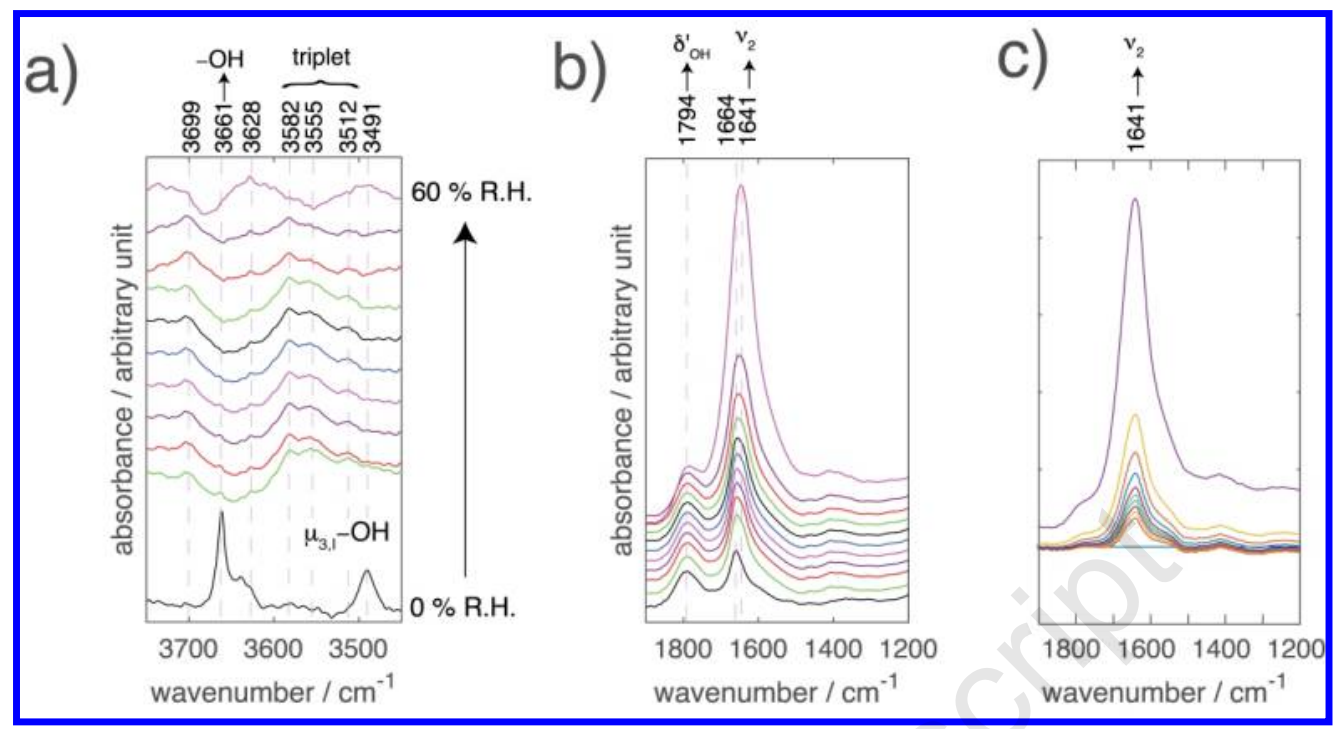




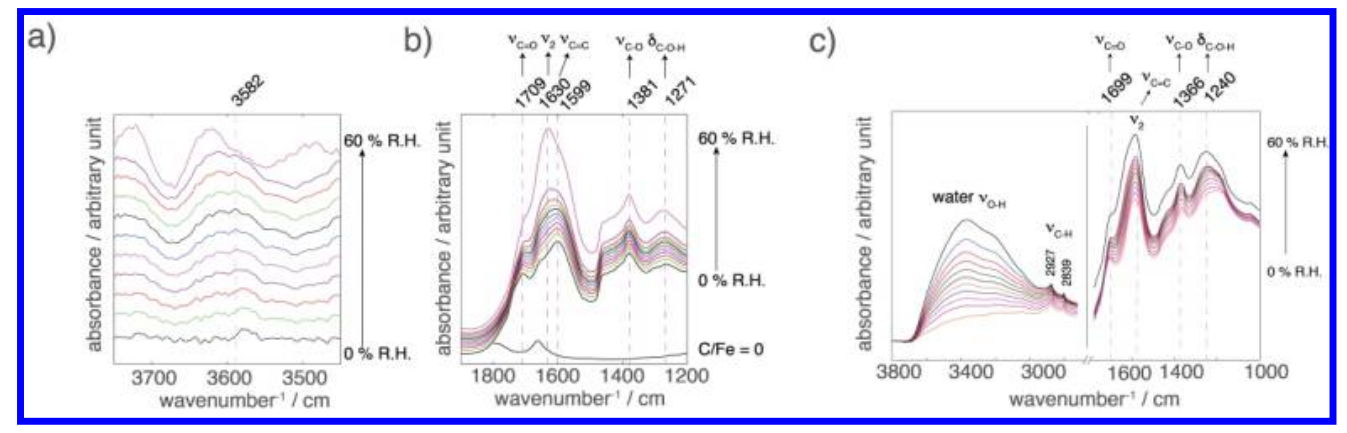

